\title{
Cancer in the offspring of radiation workers: a record linkage study
}

\author{
G J Draper, M P Little, T Sorahan, L J Kinlen, K J Bunch, A J Conquest, G M Kendall, G W Kneale, \\ R J Lancashire, C R Muirhead, C M O'Connor, T J Vincent
}

\begin{abstract}
Objectives: To test the "Gardner hypothesis" that childhood leukaemia and non-Hodgkin lymphoma can be caused by fathers' exposure to ionising radiation before the conception of the child, and, more generally, to investigate whether such radiation exposure of either parent is a cause of childhood cancer.

Design: Case-control study.

Setting: Great Britain.

Subjects: 35949 children diagnosed as having cancer, together with matched controls.
\end{abstract}

Main outcome measures: Parental employment as radiation worker as defined by inclusion in the National Registry for Radiation Workers and being monitored for external radiation before conception of child; cumulative dose of external ionising radiation for various periods of employment before conception; dose during pregnancy.

Results: After cases studied by Gardner and colleagues were excluded, fathers of children with leukaemia or non-Hodgkin lymphoma were significantly more likely than fathers of controls to have been radiation workers (relative risk 1.77, 95\% confidence interval 1.05 to 3.03 ) but there was no dose-response relation for any of the exposure periods studied; indeed, the association was greatest for those with doses below the level of detection. No increased risk was found for fathers with a lifetime preconception dose of $100 \mathrm{mSv}$ or more, or with a dose in the 6 months before conception of $10 \mathrm{mSv}$ or more. There was no increased risk for the group of other childhood cancers. Mothers' radiation work was associated with a significant increase of childhood cancer (relative risk 5.00, 1.42 to 26.94; based on 15 cases and 3 controls). Only four of the case mothers and no controls were radiation workers during pregnancy.

Conclusions: These results do not support the hypothesis that paternal preconception irradiation is a cause of childhood leukaemia and non-Hodgkin lymphoma; the observed associations may be chance findings or result from exposure to infective or other agents. If there is any increased risk for the children of fathers who are radiation workers, it is small in absolute terms: in Britain the average risk by age 15 years is 6.5 per 10000 ; our best estimate, using all available data, is that the increase is 5.4 per 10000 . For mothers, the numbers are too small for reliable estimates of the risk, if any, to be made.

\section{Introduction}

In a case-control study in west Cumbria, Gardner and colleagues found an association between leukaemia and non-Hodgkin lymphoma in young people and relatively high doses of fathers' irradiation during work at the Sellafield nuclear plant before conception of the child; they suggested that this was causal. ${ }^{12}$ We have tested this hypothesis as part of a more extensive investigation of irradiation of fathers and mothers before their children were conceived. This investigation linked the largest sets of records in Britain relating to radiation workers and to childhood cancers.

\section{Methods}

To assess the possible risks we needed first to identify among parents of children with cancer and of matched controls those who had been exposed to ionising radiation before conception of the child.

Cases of childhood cancer (diagnosed before age 15 years) were identified using the National Registry of Childhood Tumours, ${ }^{3}$ the Oxford Survey of Childhood Cancers, ${ }^{45}$ and the Scottish study of paternal preconception irradiation reported by Kinlen et al. ${ }^{6}$ Children were included if they had been born and diagnosed as having cancer in Britain in the years 1952-86; for Scotland, those with leukaemia and nonHodgkin lymphoma diagnosed in the period 1987-90 were also included. We consider that ascertainment was virtually complete for leukaemia and very high for other cancers.

The aim of this study, to test the Gardner hypothesis, required excluding the cases from which this hypothesis was derived. For this purpose, we applied the definition used by Gardner and colleagues-namely, children with leukaemia and nonHodgkin lymphoma born in the West Cumbria Health District and diagnosed there in the years 1950-85 (though they also included cases aged 15-24 years).
Childhood Cancer Research Group, University of Oxford, Oxford OX2 6HJ

G J Draper, director K J Bunch, research officer C M O'Connor, study coordinator T J Vincent, research officer

National Radiological Protection Board, Chilton, Didcot OX11 0RQ M P Little, principal scientific officer

A J Conquest, higher scientific officer G M Kendall, head of population exposure department C R Muirhead, principal scientific officer

Institute of Occupational Health, University of Birmingham, Birmingham B15 2TT T Sorahan, reader in occupational epidemiology

CRC Cancer Epidemiology Research Group, Department of Public Health, University of Oxford, Radcliffe Infirmary, Oxford OX2 $6 \mathrm{HE}$ L J Kinlen, director continued over BMJ 1997;315:1181-8 
Department of Public Health and Epidemiology, University of Birmingham, Birmingham B15 2TT

G W Kneale, research fellow R J Lancashire, computer officer

Correspondence to: DrDraper gjd@ ccrg.ox.ac.uk

\section{Selection of controls}

For the majority of cases, the Office of Population Censuses and Surveys selected a control from the birth register for the same area of birth, matched on sex and born within 6 months of the case. ${ }^{7}$ For some of the cases of childhood cancer in the study, controls were already available from two previous studies: (a) the Oxford Survey of Childhood Cancers, a nationwide case-control study of aetiology which, since 1975, has been located at the University of Birmingham and in which interviews were sought with the parents of all children who died of cancer in Britain between 1953 and 1981; for each case child, a control matched for sex and date of birth was selected from the birth register of the local authority area of residence of the case parents at the time of the interview; and (b) the Scottish study of leukaemia and non-Hodgkin lymphoma in relation to preconception irradiation by Kinlen et al (but of fathers only), in which for each case child, three controls of the same sex were selected from birth registers of the (pre-1974) county of the case ${ }^{6}$; for the present study a further set of Scottish controls, one per case, was chosen and identifying information for mothers abstracted for case and control.

\section{Tracing parental details}

To carry out the record linkage described below we needed to obtain identifying information on the parents of cases and controls. The necessary details were already available for cases (and their controls) who had been included in the Oxford Survey of Childhood Cancers. Information on fathers was available for cases and controls in the Scottish study. For the remaining subjects, born in 1966 or later, parental names were available from the birth registers and, whenever possible, the Office of Population Censuses and Surveys identified (but did not release to us) parental dates of birth from the confidential part of the computerised birth records; for those born before 1966, parental names (but not parental dates of birth) were available from birth records.

\section{The National Registry for Radiation Workers}

The National Registry for Radiation Workers holds information on more than 120000 individuals in the United Kingdom for whom dose records have been kept. The register covers individuals who were issued with a dosemeter, although this does not necessarily mean that detectable occupational exposure to radiation was received. The register holds personal and dose data on individuals, including recorded exposures to external radiation, with indicators of any monitoring for internal contamination. ${ }^{78}$

\section{Record linkage}

Computerised record linkage was used to compare identifying data for parents of cases and controls with that for radiation workers. The system used was based on the Generalised Iterative Record Linkage System developed at the National Cancer Institute of Canada, modified for the present study. ${ }^{9}$ Records were compared for possible linkage by assigning a score based on the outcome of comparing individual items of data, taking into account the frequency of the values for each item. Pairs of records with a score above a preset level were then scrutinised, using any further available identifying information to decide whether it was reasonable to conclude that the two records related to the same person.

Because of the legal confidentiality of certain data, linkage of parents of children born in England or Wales from 1966 onwards was carried out at the Office of Population Censuses and Surveys using dates of birth from the confidential part of the computerised primary birth records. For the remainder, the record linkages were carried out at the National Radiological Protection Board. For parents whose records were not traced on the computer birth tapes, or whose birth dates were not available (pre-1966 records), the computerised phase of the record linkage was based on comparisons of surnames and given name(s) only; possible matches were then scrutinised as descibed above. Methodological questions relevant to the record linkage aspects of this study are discussed elsewhere. ${ }^{79}$

\section{Details of exposure to radiation}

In most instances, radiation doses are stored as annual totals on the National Registry for Radiation Workers. For linked parents, additional information was sought from participating organisations for the calendar years shortly before and after the child's conception (for fathers) or birth (for mothers): this included dosemeter assessments of external whole body doses, together with details of any dose corrections applied and information about monitoring for exposure from internal emitters during the period of special interest, together with either the corresponding details for earlier years or an indication of whether such monitoring had taken place.

For the linked parents and for the corresponding father or mother of the matched case or control, external doses were calculated for (i) the total period before conception; (ii) the six months before conception (fathers' exposures); (iii) the three months before conception (fathers' exposures); and (iv) the relevant pregnancy (mothers' exposures).

The total and 6 month preconception periods were chosen because these were the periods analysed by Gardner et al. ${ }^{12}$ As in the studies by Kinlen ${ }^{6}$ and the Health and Safety Executive, ${ }^{10}{ }^{11}$ the 3 month preconception period was also considered because it corresponds with the time needed for all the stages of spermatogenesis. ${ }^{12}$ The date of conception was taken to be 270 days before the birth of the child. The best estimate of external dose involves corrections for factors such as the dose threshold of the dosemeter. ${ }^{8}$ To examine the sensitivity of the analyses to the corrections applied, uncorrected external doses were also calculated for each of the periods listed above.

For categorical analyses of preconception doses, similar dose categories to those chosen by Gardner and colleagues were used (see tables 3 and 5). We have also included a category of individuals who, though monitored, had a dose that was either zero or below the detection level of the recording device. This category was not considered separately in the Scottish study.

Information was also recorded on the industrial classification of the parent, ${ }^{8}$ the last site of employment at or before the time of conception, whether the parent was ever employed at Sellafield before conception, and, for mothers, whether she continued to be a radiation worker while pregnant with the child. 


\section{Statistical methods}

For this study a parent was defined as a radiation worker if he or she was included on the National Registry for Radiation Workers and was monitored for external radiation before conception of the child included in the study. Only case-control sets in which a parent of either a case or control was a radiation worker can contribute information relevant to the estimation of the relative risks of childhood cancer among the offspring of such workers. The statistical methods are exemplified by table 3, where individual dose categories are analysed, and table 4, where different categories of worker are compared. A central concept in our analysis was the effect of "adjustment for radiation worker status." Such adjustment was carried out to determine whether an apparent radiation effect arose from there being different risks associated with different doses or simply from differences between radiation workers (irrespective of dose) and others. Exact methods were used for the principal categorical analyses, as explained elsewhere ${ }^{7}$; the LogXact statistical package was used..$^{13}$ Additional analyses using conditional logistic regression were carried out by means of the PECAN statistical package. ${ }^{14} 15$

\section{Results}

A total of 35949 children with cancer were included in the study, together with 38323 control children. Table 1 gives details for the three component datasets. The various linkage procedures identified a total of 161 fathers (82 cases, 79 controls) and 18 mothers (15 cases, 3 controls) for whom preconception exposure details were available (table 2). For fathers no straightforward conclusions can be drawn from a comparison of the number of linked cases and controls because some of the cases had one control and some had three. The 32 subjects from the Scottish study include all the fathers previously reported in the dose categories $50.0-99.9 \mathrm{mSv}$ and $\geqslant 100.0 \mathrm{mSv}$, though, after reviews, the dose of one control father moved from the $50.0-99.9$ to the $0.1-49.9 \mathrm{mSv}$ category.

\section{Fathers' radiation exposure}

In the present study our main concern was to determine whether the findings of Gardner et $\mathrm{al}^{12}$ relating paternal preconception irradiation to childhood leukaemia and non-Hodgkin lymphoma could be confirmed with independent data. To this end, the west Cumbrian data from which the Gardner hypothesis was derived have been excluded from table 3, which shows relative risks for the radiation dose categories described in the previous section. Of the 12 relative risks examined for leukaemia and nonHodgkin lymphoma, the only significantly raised values are for the zero and subthreshold dose category $(<0.1 \mathrm{mSv})$ of total preconception exposure (for which the $95 \%$ confidence interval for the relative risk is 1.18 to $\infty$, based on 6 case and 0 control fathers) and the 0.1-2.4 $\mathrm{mSv}$ dose category in the 3 month preconception period (relative risk 2.82, 1.10 to 7.82; based on 16 case and 11 control fathers). The relative risk for a total preconception dose of $100 \mathrm{mSv}$ or more is 0.46 (0.01 to 5.17; based on 1 case and 4 control fathers). Relative risks for cancers other than leukaemia and non-Hodgkin lymphoma, together with those for all
Table 1 Numbers of case and control fathers and mothers

\begin{tabular}{lrrrrrrrr} 
& \multicolumn{3}{c}{ Cases } & & \multicolumn{3}{c}{ Controls } \\
\cline { 2 - 3 } Source & Children & Fathers & Mothers & & Children & Fathers & Mothers \\
\hline NRCT & 26379 & 25070 & 26379 & & 26379 & 25070 & 26379 \\
\hline OSCC & 8383 & 8281 & 8351 & & 8383 & 8281 & 8351 \\
\hline Kinlen et al & 1187 & 1187 & $918^{*}$ & & 3561 & 3561 & $918^{*}$ \\
\hline Total & 35949 & 34538 & 35648 & & 38323 & 36912 & 35648 \\
\hline
\end{tabular}

NRCT=National Registry of Childhood Tumours; including Scottish children not covered by Kinlen et al. ${ }^{6}$ OSCC=0xford Survey of Childhood Cancers; including Scottish children not covered by Kinlen et al. ${ }^{6}$ ${ }^{*}$ Included here, but not studied by Kinlen et al. ${ }^{6}$

Table 2 Numbers of case and control parents with preconception dose records found in the National Registry for Radiation Workers

\begin{tabular}{lccccc} 
& \multicolumn{2}{c}{ Fathers } & & \multicolumn{2}{c}{ Mothers } \\
\cline { 2 - 3 } \cline { 5 - 6 } & Cases & Controls & & Cases & Controls \\
\hline NRCT and 0 SCC $^{*}$ & 72 & 57 & & 15 & 3 \\
\hline Kinlen et al & 10 & $22 \dagger$ & & - & - \\
\hline Total & 82 & 79 & & 15 & 3 \\
\hline
\end{tabular}

${ }^{\star}$ National Registry of Childhood Tumours and the Oxford Survey of Childhood Cancers (including Scottish children not covered by Kinlen et al ${ }^{6}$ ).

†See note on numbers of controls at beginning of results section.

Table 3 Relative risks for childhood cancer by dose categories of radiation exposure of fathers before child's conception (excluding children with leukaemia and non-Hodgkin lymphoma in study of Gardner et al ${ }^{1}$ and their controls)

\begin{tabular}{|c|c|c|c|}
\hline Variable & $\begin{array}{l}\text { No of } \\
\text { cases }\end{array}$ & $\begin{array}{l}\text { No of } \\
\text { controls }\end{array}$ & Relative risk $(95 \% \mathrm{Cl})^{*}$ \\
\hline \multicolumn{4}{|c|}{ Leukaemia and non-Hodgkin lymphoma (13 621 cases, 15 995† controls) } \\
\hline Non-radiation workerł & 13581 & 15957 & 1.0 \\
\hline \multicolumn{4}{|c|}{ Total preconception dose (mSv): } \\
\hline$<0.1$ & 6 & 0 & $8.17(1.18$ to $\infty) \S$ \\
\hline $0.1-49.9$ & 29 & 32 & $1.47(0.81$ to 2.68$)$ \\
\hline $50.0-99.9$ & 4 & 2 & $4.49(0.60$ to 51.98$)$ \\
\hline$\geqslant 100.0$ & 1 & 4 & $0.46(0.01$ to 5.17$)$ \\
\hline \multicolumn{4}{|c|}{ Dose in 6 months before conception (mSv): } \\
\hline$<0.19$ & 20 & 19 & 1.61 (0.77 to 3.38$)$ \\
\hline $0.1-4.9$ & 17 & 14 & $2.12(0.91$ to 5.13$)$ \\
\hline $5.0-9.9$ & 1 & 1 & $1.73(0.02$ to 156.4$)$ \\
\hline$\geqslant 10.0$ & 2 & 4 & $1.33(0.10$ to 12.76$)$ \\
\hline \multicolumn{4}{|c|}{ Dose in 3 months before conception (mSv): } \\
\hline$<0.11$ & 22 & 22 & 1.48 (0.73 to 3.01$)$ \\
\hline $0.1-2.4$ & 16 & 11 & 2.82 (1.10 to 7.82$)$ \\
\hline $2.5-4.9$ & 0 & 2 & $0.73(0.00$ to 11.09$)$ \\
\hline$\geqslant 5.0$ & 2 & 3 & $1.73(0.11$ to 26.23$)$ \\
\hline
\end{tabular}

All cancers excluding leukaemia and non-Hodgkin lymphoma (20 889 cases, 20889 controls)

\begin{tabular}{lllr}
\hline Non-radiation worker $\ddagger$ & 20856 & 20854 & 1.0
\end{tabular}

Total preconception dose $<\mathrm{mSv}$ ):

\begin{tabular}{lrrl}
\hline$<0.1$ & 1 & 2 & 0.49 (0.01 to 9.48$)$ \\
\hline $0.1-49.9$ & 27 & 28 & $0.95(0.54$ to 1.68$)$ \\
\hline $50.0-99.9$ & 3 & 3 & $0.99(0.13$ to 7.41$)$ \\
\hline$\geqslant 100.0$ & 2 & 2 & 1.00 (0.07 to 13.77) \\
\hline
\end{tabular}

All cancers (34 510 cases, 36884 controls)

Non-radiation workerł

$34437 \quad 36811$

Total preconception dose (mSv):

\begin{tabular}{lrrl}
\hline$<0.1$ & 7 & 2 & 3.57 (0.68 to 35.29$)$ \\
\hline $0.1-49.9$ & 56 & 60 & 1.20 (0.80 to 1.80$)$ \\
\hline $50.0-99.9$ & 7 & 5 & $2.09(0.55$ to 8.76$)$ \\
\hline$\geqslant 100.0$ & 3 & 6 & 0.69 (0.11 to 3.43$)$ \\
\hline
\end{tabular}

${ }^{*}$ Calculated with LogXact. ${ }^{13}$

tSee note on numbers of controls at beginning of results section.

‡No radiation dose recorded with the National Registry for Radiation Workers before conception of the survey child. All relative risks are calculated using this as the reference group.

SConditional maximum-likelihood estimate is not available because the sufficient statistic is at one extreme of its range. The median unbiased point estimate is shown instead. ${ }^{13}$

IIncludes also members of the NRRW who only had radiation doses before the stated time period. 
Table 4 Relative risks for childhood cancer for paternal radiation workers overall and by type of radiation work (excluding children with leukaemia and non-Hodgkin lymphoma in study of Gardner et al ${ }^{1}$ and their controls)

Relative risk $(95 \% \mathrm{Cl})^{*}$

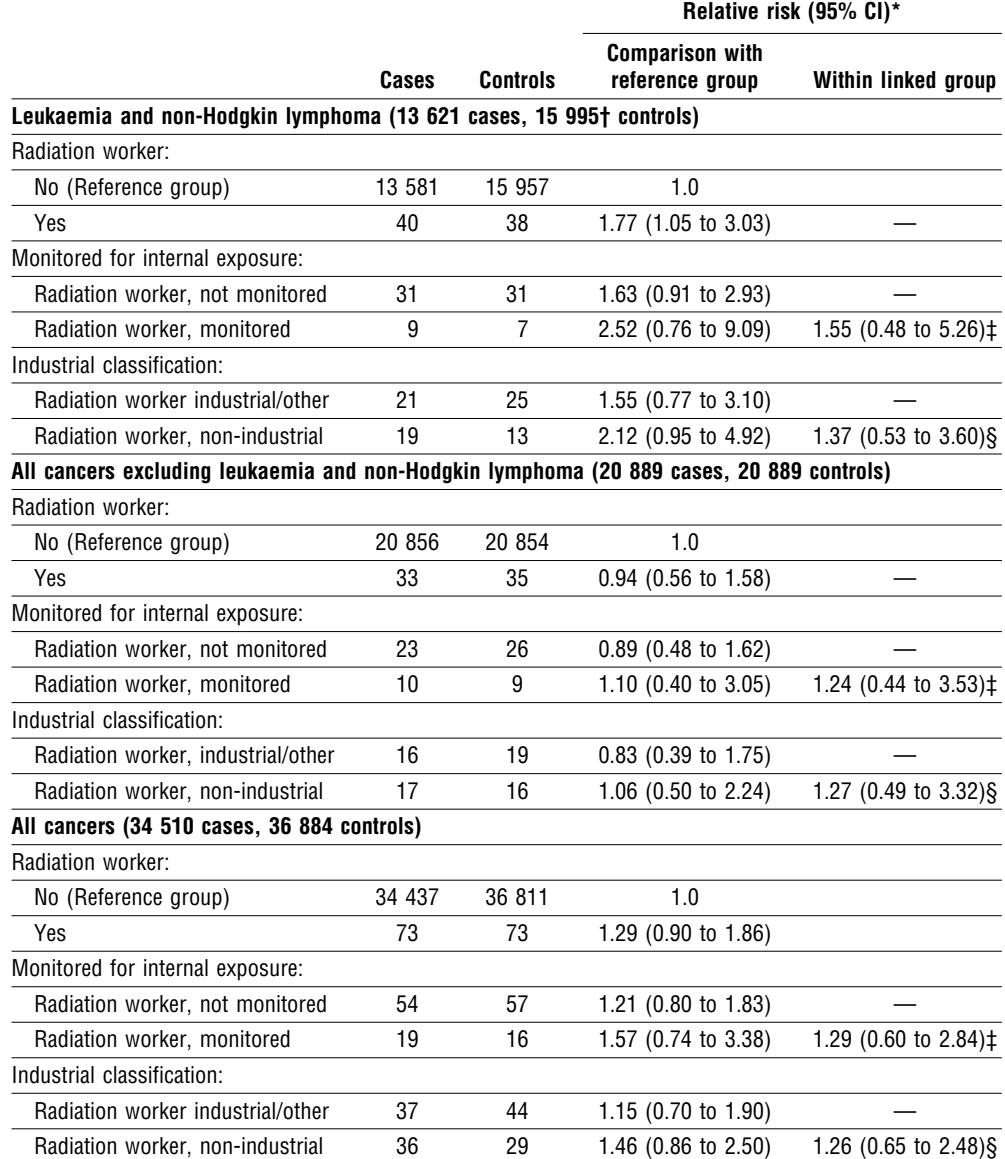

${ }^{*}$ Calculated with LogXact. ${ }^{13}$

$\dagger$ See note on numbers of controls at beginning of Results section

$\ddagger$ Relative risk of monitored versus not monitored for internal exposure, adjusted for paternal radiation work (yes/no), calculated using conditional logistic regression in PECAN ${ }^{15}$ because LogXact statistic was uninformative.

§Relative risk of non-industrial versus industrial/other classification, adjusted for paternal radiation work (yes/no), calculated using conditional logistic regression in PECAN ${ }^{15}$ because LogXact statistic was uninformative.
The effect of including the cases in the study of Gardner et al was also examined (table 5). The relative risk of leukaemia and non-Hodgkin lymphoma for a total preconception dose of $100 \mathrm{mSv}$ or more was 1.43 (0.26 to 7.18). Other relative risks did not differ greatly from those excluding the Gardner cases (table 3). When dose was treated as a continuous variable, the relative risk of leukaemia and non-Hodgkin lymphoma for a total preconception dose of $100 \mathrm{mSv}$ was 2.13 (1.02 to 5.13); this risk was reduced to 1.52 ( 0.71 to 3.76$)$ after radiation worker status was adjusted for. There were no significant relations between dose and risk for the 6 month and 3 month preconception doses. $^{7}$ The relative risk for radiation workers irrespective of dose received was 1.83 (1.11 to 3.04); see report. ${ }^{7}$

\section{Mother's radiation exposure}

Table 6 shows relative risks for maternal dose categories, both for total preconception doses and for doses received during the relevant pregnancy (see discussion below). The analyses are based on small numbers, and none of the relative risks is statistically significant. There were no significant trends with any maternal dose variables after adjustment for maternal radiation worker status. ${ }^{7}$ Relative risks for maternal radiation workers overall and by type of work are shown in table 7. For childhood leukaemia and

Table 5 Relative risks for childhood cancer and paternal preconception dose categories: full national dataset including children with leukaemia and non-Hodgkin lymphoma in study of Gardner et $\mathrm{al}^{1}$ and their controls

\begin{tabular}{|c|c|c|c|}
\hline Variable & $\begin{array}{l}\text { No of } \\
\text { cases }\end{array}$ & $\begin{array}{c}\text { No of } \\
\text { controls }\end{array}$ & $\begin{array}{c}\text { Relative risk } \\
(95 \% \mathrm{Cl})^{\star}\end{array}$ \\
\hline \multicolumn{4}{|c|}{ Leukaemia and non-Hodgkin lymphoma (13 649 cases, 16 023† controls) } \\
\hline $\begin{array}{c}\text { Non-radiation } \\
\text { worker }\end{array}$ & 13600 & 15979 & 1.0 \\
\hline \multicolumn{4}{|c|}{ Total preconception dose(mSv): } \\
\hline$<0.1$ & 6 & 0 & $8.17(1.18$ to $\infty) \S$ \\
\hline $0.1-49.9$ & 32 & 36 & $1.45(0.82$ to 2.55$)$ \\
\hline $50.0-99.9$ & 7 & 3 & $4.22(0.91$ to 26.46$)$ \\
\hline$\geqslant 100.0$ & 4 & 5 & $1.43(0.26$ to 7.18$)$ \\
\hline
\end{tabular}

cancers, are also shown in table 3; none of these relative risks is significantly different from unity.

No significant trends in risk with dose treated as a continuous variable were found for any of the diagnostic groups or periods studied. For leukaemia and nonHodgkin lymphoma, the relative risk for a total preconception dose of $100 \mathrm{mSv}$ was 1.62 (0.59 to 4.84) which was reduced to 0.92 (0.28 to 2.98$)$ after adjustment for radiation worker status.

Estimates of risk for radiation workers irrespective of the doses received are given in table 4 . For leukaemia and non-Hodgkin lymphoma, radiation workers overall showed a relative risk of 1.77 (1.05 to 3.03). The risk was somewhat greater for workers who had been monitored for internal deposition of radionuclides than for other workers, but not significantly so. Relative risks were similar for industrial and non-industrial workers. For other cancers, relative risks were close to unity.

Other variables were also considered (postnatal radiation dose, age and year of birth of the child), and analyses were also carried out using various combinations of these. The results of these analyses are presented in the full report. ${ }^{7}$ None of them changes the conclusions presented here.
Dose in 6 months before conception (mSv):

\begin{tabular}{lrrr}
\hline$<0.1 \|$ & 20 & 21 & $1.41(0.69$ to 2.88$)$ \\
\hline $0.1-4.9$ & 21 & 16 & $2.35(1.06$ to 5.47$)$ \\
\hline $5.0-9.9$ & 3 & 2 & $2.29(0.24$ to 29.33$)$ \\
\hline$\geqslant 10.0$ & 5 & 5 & $2.48(0.50$ to 13.32$)$
\end{tabular}

Dose in 3 months before conception (mSv):

\begin{tabular}{lrrl}
\hline$<0.1 \rrbracket$ & 22 & 24 & $1.31(0.66$ to 2.60$)$ \\
\hline $0.1-2.4$ & 20 & 12 & $3.38(1.37$ to 9.16$)$ \\
\hline $2.5-4.9$ & 1 & 4 & $0.48(0.01$ to 5.86$)$ \\
\hline$\geqslant 5.0$ & 6 & 4 & $2.61(0.47$ to 17.88$)$
\end{tabular}

All cancers (34 538 cases, 36912 controls)

worker

Total preconception dose (mSv):

\begin{tabular}{lrrr}
\hline$<0.1$ & 7 & 2 & $3.57(0.68$ to 35.17$)$ \\
\hline $0.1-49.9$ & 59 & 64 & $1.19(0.80$ to 1.76$)$ \\
\hline $50.0-99.9$ & 10 & 6 & $2.33(0.74$ to 8.09$)$ \\
\hline$\geqslant 100.0$ & 6 & 7 & $1.19(0.32$ to 4.29$)$
\end{tabular}

${ }^{*}$ Calculated with $\log X a c t .{ }^{13}$

†See note on numbers of controls at beginning of results section.

fNo radiation dose recorded with the National Registry for Radiation Workers before conception of thesurvey child. All relative risks are calculated using this as the reference group.

$\S$ Conditional maximum likelihood estimate is not available because the sufficient statistic is at one extreme of its range. The median unbiased point estimate is shown instead. ${ }^{13}$

IIncludes also members of the National Registry for Radiation Workers who had radiation doses only before the stated time period.

\begin{tabular}{llll}
\hline Non-radiation & 34456 & 36833 & 1.0
\end{tabular}


Table 6 Relative risks for childhood cancer by mother's radiation dose before child's conception and while pregnant

\begin{tabular}{|c|c|c|c|}
\hline Variable & $\begin{array}{l}\text { No of } \\
\text { cases }\end{array}$ & $\begin{array}{c}\text { No of } \\
\text { controls }\end{array}$ & $\begin{array}{c}\text { Relative risk } \\
(95 \% \text { CI })^{*}\end{array}$ \\
\hline \multicolumn{4}{|c|}{ Leukaemia and non-Hodgkin lymphoma (13 859 cases, 13859 controls) } \\
\hline Non-radiation worker† & 13855 & 13858 & 1.0 \\
\hline \multicolumn{4}{|c|}{ Total preconception dose (mSv): } \\
\hline$<0.1$ & 0 & 0 & - \\
\hline $0.1-4.9$ & 3 & 1 & - \\
\hline $5.0-49.9$ & 1 & 0 & - \\
\hline$\geqslant 50.0$ & 0 & 0 & - \\
\hline \multicolumn{4}{|c|}{ Radiation worker during pregnancy: $\ddagger$} \\
\hline No & 4 & 1 & $4.00(0.40$ to 196.5$)$ \\
\hline Yes & 0 & 0 & - \\
\hline
\end{tabular}

All cancers excluding leukaemia and non-Hodgkin lymphoma (21 789 cases, 21789 controls)

\begin{tabular}{lccc}
\hline Non-radiation worker $\dagger$ & 21778 & 21787 & 1.0 \\
\hline Total preconception dose $(\mathrm{mSv}):$ & & & \\
\hline$<0.1$ & 2 & 0 & - \\
\hline $0.1-4.9$ & 6 & 2 & - \\
\hline $5.0-49.9$ & 2 & 0 & - \\
\hline$\geqslant 50.0$ & 1 & 0 & - \\
\hline
\end{tabular}

Radiation worker during pregnancy:

\begin{tabular}{lllc}
\hline No & 7 & 2 & $3.50(0.67$ to 34.57$)$ \\
\hline Radiation dose $(\mathrm{mSv}):$ & & & - \\
\hline$<0.1$ & 2 & 0 & - \\
\hline $0.1-0.9$ & 1 & 0 & - \\
\hline $1.0-1.9$ & 0 & 0 & - \\
\hline$\geqslant 2.0$ & 1 & 0 & $5.29(0.66$ to $\infty) \S$ \\
\hline All dose levels & 4 & 0 &
\end{tabular}

\section{All cancers (35 648 cases, 35648 controls)}

\begin{tabular}{llll}
\hline Non-radiation worker† & 35633 & 35645 & 1.0
\end{tabular}

Total preconception dose (mSv):

\begin{tabular}{llll}
\hline$<0.1$ & 2 & 0 & - \\
\hline $0.1-4.9$ & 9 & 3 & - \\
\hline $5.0-49.9$ & 3 & 0 & - \\
\hline$\geqslant 50.0$ & 1 & 0 & - \\
\hline
\end{tabular}

Radiation worker during pregnancy:

\begin{tabular}{lllc}
\hline No & 11 & 3 & $3.67(0.97$ to 20.44$)$ \\
\hline Radiation dose $(\mathrm{mSv}):$ & & & \\
\hline$<0.1$ & 2 & 0 & - \\
\hline $0.1-0.9$ & 1 & 0 & - \\
\hline $1.0-1.9$ & 0 & 0 & - \\
\hline$\geqslant 2.0$ & 1 & 0 & - \\
\hline All dose levels & 4 & 0 & $5.29(0.66$ to $\infty) \S$ \\
\hline
\end{tabular}

${ }^{*}$ Calculated with LogXact. ${ }^{13}$

†No radiation dose recorded with the National Registry for Radiation Workers before the conception of the survey child. All relative risks are calculated using this as the reference group.

fln utero doses were obtained only for women who were monitored before conception.

§Conditional maximum-likelihood estimate is not available because the sufficient statistic is at one extreme of its range. The median unbiased point estimate is shown instead. ${ }^{13}$

non-Hodgkin lymphoma, radiation workers overall showed a non-significantly raised risk of 4.00 (0.40 to 196.5); for other childhood cancers there was a significantly increased relative risk of 5.50 (1.20 to 51.02); for all cancers taken together the relative risk was 5.00 (1.42 to 26.94). The observed excess was not concentrated within any one diagnostic group.

\section{Discussion}

\section{The Gardner hypothesis}

The report of an excess of leukaemia and nonHodgkin lymphoma among young people born (and diagnosed) in west Cumbria whose fathers had relatively high radiation exposures before their conception (paternal preconception irradiation) $)^{12}$ had a major impact. The causal interpretation suggested for this unexpected finding is referred to here as the Gardner hypothesis. Our analyses to test this hypothesis necessarily exclude the Gardner cases. We found an increased risk of childhood leukaemia and non-Hodgkin lymphoma among the children of radiation workers, but our most important finding is that this risk was not related to dose; indeed, the association was greatest for children of workers with doses below the level of detection. Furthermore, we did not find a significantly increased risk in the highest dose category for any of the periods considered: for a cumulative preconception dose of $100 \mathrm{mSv}$ and over, we found a relative risk of 0.46 ( 0.01 to 5.17 ) in contrast with 8.59 (1.41 to 52.20) reported by Gardner et al using local (parish) controls' ${ }^{2}$ for doses above $10 \mathrm{mSv}$ in the 6 months before conception, for which Gardner et al reported a relative risk of 4.50 (1.08 to 18.78), again we found no significant increase in risk (1.33; 0.10 to 12.76). Similarly, we found no significant increase for doses above $5.0 \mathrm{mSv}(1.73 ; 0.11$ to 26.23$)$ in the 3 months before conception, a biologically more relevant period (though not considered by Gardner et al). Even when the Gardner cases were included, there was no significant excess in any of the highest preconception exposure categories considered here. This study therefore found no support for the hypothesis that paternal preconception irradiation is a cause of childhood leukaemia and non-Hodgkin lymphoma.

Table 7 Relative risks for childhood cancer for mothers who were radiation workers overall and by type of radiation work

\begin{tabular}{|c|c|c|c|}
\hline & Cases & Controls & Relative risk $(95 \% \mathrm{CI})^{*}$ \\
\hline \multicolumn{4}{|c|}{ Leukaemia and non-Hodgkin lymphoma (13 859 cases, 13859 controls) } \\
\hline \multicolumn{4}{|l|}{ Radiation worker: } \\
\hline No (reference group) & 13855 & 13858 & 1.0 \\
\hline Yes & 4 & 1 & $4.00(0.40$ to 196.5$)$ \\
\hline \multicolumn{4}{|l|}{ Monitored for internal exposure: } \\
\hline Radiation worker, not monitored & 4 & 1 & $4.00(0.40$ to 196.5$)$ \\
\hline Radiation worker, monitored & 0 & 0 & $-\dagger$ \\
\hline \multicolumn{4}{|l|}{ Industrial classification: } \\
\hline Radiation worker industrial/other & 0 & 0 & $-\dagger$ \\
\hline Radiation worker, non industrial & 4 & 1 & $4.00(0.40$ to 196.5$)$ \\
\hline \multicolumn{4}{|c|}{ All cancers excluding leukaemia and non-Hodgkin lymphoma (21 789 cases, 21789 controls) } \\
\hline \multicolumn{4}{|l|}{ Radiation worker: } \\
\hline No (reference group) & 21778 & 21787 & 1.0 \\
\hline Yes & 11 & 2 & $5.50(1.20$ to 51.02$)$ \\
\hline \multicolumn{4}{|l|}{ Monitored for internal exposure: } \\
\hline Radiation worker, not monitored & 11 & 1 & $11.00(1.60$ to 473.0$)$ \\
\hline Radiation worker, monitored & 0 & 1 & $1.00(0.00$ to 39.10$)$ \\
\hline \multicolumn{4}{|l|}{ Industrial classification: } \\
\hline Radiation worker industrial/other & 4 & 2 & $2.00(0.29$ to 22.11$)$ \\
\hline Radiation worker, non-industrial & 7 & 0 & $9.61(1.44$ to $\infty) \ddagger$ \\
\hline
\end{tabular}

\section{All cancers (35 648 cases, 35648 controls)}

Radiation worker:

\begin{tabular}{lccc}
\hline No (reference group) & 35633 & 35645 & 1.0 \\
\hline Yes & 15 & 3 & $5.00(1.42$ to 26.94) \\
\hline Monitored for internal exposure: & & & \\
\hline Radiation worker, not monitored & 15 & 2 & $7.50(1.74$ to 67.71$)$ \\
\hline Radiation worker, monitored & 0 & 1 & $1.00(0.00$ to 39.10$)$ \\
\hline Industrial classification: & & & \\
\hline Radiation worker industrial/other & 4 & 2 & $2.00(0.29$ to 22.11) \\
\hline Radiation worker, non-industrial & 11 & 1 & $11.00(1.60$ to 473.0) \\
\hline
\end{tabular}

${ }^{*}$ Calculated with LogXact. ${ }^{13}$

Insufficient data to calculate relative risk.

tConditional maximum likelihood estimate is not available because the sufficient statistic is at one extreme of its range. The median unbiased point estimate is shown instead. ${ }^{13}$ 
Similarly, no support has been reported in studies of the offspring of (a) occupationally exposed groups in Canada, ${ }^{16}$ Scotland, ${ }^{6}$ England, ${ }^{17}{ }^{18}$ Germany, ${ }^{19}$ or France $^{20} ;(b)$ individuals who received the diagnostic contrast medium Thorotrast ${ }^{21}$; or (c) offspring of the Japanese atomic bomb survivors. ${ }^{22-24}$ Little has highlighted the discrepancy between the leukaemia risk associated with preconception irradiation in the children of Sellafield workers and that found in other studies. ${ }^{22}{ }^{25}$ The study by the Health and Safety Executive $^{10}{ }^{11}$ showed that the risk in the offspring of male Sellafield workers was significantly associated with paternal preconception irradiation only for those children born in Seascale, who represent less than 10\% of the offspring. Further analyses of the association with preconception exposure in the children born in Seascale showed the risks to be statistically incompatible (two sided $\mathrm{P}<0.01$ ) with those observed in all the other major datasets of offspring. ${ }^{26} 27$

It has been suggested that the discrepancy between the findings in west Cumbria and the Japanese offspring studies ${ }^{123}$ might reflect the presence of internally deposited radionuclides in the Sellafield workforce, and in particular the radioisotopes of plutonium, that emit alpha particles, the organ doses from which were not taken into account by Gardner et al. The Danish Thorotrast study, ${ }^{21}$ however, shows that, notwithstanding its small size (no cases of leukaemia and non-Hodgkin lymphoma compared with 0.25 expected), its statistical power is high because of the large testicular doses (averaging over $1 \mathrm{~Sv}$ ). ${ }^{27} \mathrm{In}$ the Danish study the testicular dose is almost entirely due to alpha particle irradiation from internally incorporated radionuclides, in contrast with the predominantly external low linear energy transfer doses in all the other studies. Given also the lack of evidence of any risk of leukaemia or non-Hodgkin lymphoma associated with internally deposited radionuclides in the Health and Safety Executive study ${ }^{10}{ }^{11}$, alpha emitters such as plutonium can be effectively discounted as being responsible for the Seascale excess.

Several animal studies have linked paternal radiation exposure to the induction of heritable cancers, ${ }^{28-30}$ but comparable studies have yielded negative findings. ${ }^{31-33}$ There seems to be only a small heritable component in childhood leukaemia or lymphoma. ${ }^{34}$ Doll et al have pointed out inconsistencies between the Gardner hypothesis and what is known of radiation genetics. ${ }^{35}$

Father's preconception irradiation: other cancers The present study is the first, apart from that by the Health and Safety Executive of the Sellafield workers, ${ }^{1011}$ to investigate the incidence of childhood cancers other than leukaemia and non-Hodgkin lymphoma, in relation to occupational paternal preconception irradiation; no association was found. In the Sellafield study, a significant negative trend was found between the cumulative preconception dose and such cancers. ${ }^{10}{ }^{11}$ As with leukaemia, there were no significant associations among the offspring of the survivors of the Japanese atomic bombings ${ }^{23}{ }^{24}$ or in the offspring of fathers who had received Thorotrast treatment before the child was conceived. ${ }^{21}$

\section{Mother's irradiation and childhood cancer}

Fifteen mothers of children with cancer and three mothers of controls were found in the register of radiation workers; only one case mother had a lifetime preconception dose of $50 \mathrm{mSv}$ or more. Again, although there was an excess of cases as compared with controls, no dose-response relation was found. We considered the possibility that the case-control excess could be due to radiation exposure in utero. Only four women (all mothers of children with cancer other than leukaemia and non-Hodgkin lymphoma) were radiation workers while pregnant (table 6); two other women (also mothers of cases) remained in employment, though not as radiation workers, during at least part of their pregnancy. The remaining 12 linked women (9 cases and 3 controls) stopped working in the industry well before the child was conceived. (We have no information for the (presumably small) group of women who were monitored during pregnancy but not before.) Previous studies found no excess of malignancy among the offspring of mothers who had received relatively high doses of radiation from Thorotrast treatment before their conception ${ }^{21}$ or the offspring of female survivors of the atomic bombings. ${ }^{24}$ Further discussion of risks in offspring of various exposed groups is to be found in the full report.

How might the reported associations be explained? Our findings for both fathers and mothers may be due to chance or they may point to some carcinogenic risk for offspring associated with radiation work other than radiation itself. Radiation workers are potentially exposed to various chemicals, but no chemical is known to have this effect in humans. ${ }^{36}$

The association found by Gardner and his colleagues between relatively high doses of paternal preconception irradiation and childhood leukaemia and non-Hodgkin lymphoma was restricted to the village of Seascale in west Cumbria ${ }^{12}{ }^{10}$ and may be due to chance. In this village there was an excess of these diseases in the age group 0-24 years which was unlikely to be due to chance, was not explained by Gardner's findings,$^{38}$ and involved children both of workers who had doses only after the conception and of non-radiation workers. The most likely explanation for the Seascale excess seems to be infection promoted by population mixing, a hypothesis originating largely in that excess. ${ }^{39}$ The hypothesis builds on the longstanding suspicion that an (unidentified) infection underlies childhood leukaemia but postulates that this disease is a rare response to that infection. The population mixing hypothesis, which has been supported by studies in Britain $^{40-42}$ and in other countries, ${ }^{43-45}$ predicts that the effects of such mixing would be particularly great in Seascale because of its highly unusual demography. ${ }^{41}{ }^{46}$ The population mixing hypothesis may also be relevant to the findings of the present study, at least for leukaemia and non-Hodgkin lymphoma. Radiation workers may be subject to unusual opportunities for population mixing and the spread of oncogenic infections, since many workers are brought together from different geographical origins to work in rural and often isolated areas; furthermore, there is appreciable movement by workers among different plants within Britain. In addition, areas in the vicinity of certain nuclear sites (notably Dounreay ${ }^{47}$ and Aldermaston ${ }^{48}$ ) 
have been exposed to unusual levels of population mixing for reasons unconnected with radiation work. It is relevant that certain studies of population mixing have pointed to adult transmission of infection in the aetiology of childhood leukaemia and non-Hodgkin lymphoma. ${ }^{404} 47$

So far, studies of population mixing in relation to childhood malignancy have been limited to leukaemia and non-Hodgkin lymphoma. The fivefold increase of childhood cancer associated with female radiation workers (based on 15 cases and 3 controls) is greater than the increase of leukaemia found generally in studies of population mixing. ${ }^{40}{ }^{41}$ It is not clear whether such studies are relevant to other cancers.

\section{Conclusion}

The results of this study do not support the hypothesis that paternal preconception irradiation is a cause of childhood leukaemia and non-Hodgkin lymphoma; nor was any association found between such radiation and other childhood cancers. However, an increased incidence of childhood leukaemia and non-Hodgkin lymphoma unrelated to dose of radiation was found among the children of male workers, and an increased incidence of childhood cancer in general, again unrelated to dose, was found among children of female workers. The observed associations may be chance findings or result from exposure to infective or other agents. If there is any increased risk of leukaemia and non-Hodgkin lymphoma for the children of fathers who are radiation workers it is small in absolute terms: in Britain the average risk by age 15 years is 6.5 per 10000 ; our best estimate, based on the relative risk estimate of 1.83 that includes the Gardner cases, is that the increase is 5.4 per 10000 . For mothers the numbers are too small for reliable estimates of the risk, if any, to be made.

We acknowledge the help of Maureen Baverstock, Christine Fitz-John, Martin King, Hilary Bradshaw, Janice Rogers, and Charles Stiller at the Childhood Cancer Research Group, Oxford; Bev Botting, Dorothy Lewis and staff, Janice Snow, Sue Dewane, Stephen Morse, and Andy Roberts at the Office of Population Censuses and Surveys, Southport; and Alison Horsburgh, Josie Stephenson, Vicky Stephenson, and Soula Caldwell in Register House, Edinburgh.

We wish to thank the workforces and managements of the organisations participating in the National Registery for Radiation Workers for their cooperation with this study. Thanks are also due to Julia Thomas, Adrian Goodill, Judy Vokes, and Richard Haylock at the National Radiological Protection Board, and to Eric Greenslade, who visited the organisations' dose record keeping sections to collect and audit the additional dose data; also, we wish to express our appreciation for the assistance of Richard Wakeford. We are grateful for the time and effort that the participating organisations devoted to the collection of these data; particular thanks are due to Alan Britcher, Barry Cripwell, Wyn Davies, Paul Foster, Kevin Harrison, Gerry Harte, Graham Hughes, Sheila Jones, Bob Kafka, Dallas Law, Peter Lea, David Perry, Len Salmon, and David Smith. We would also like to acknowledge the contributions made by Dr Barbara MacGibbon in setting up this study and Mark Webb in its early stages.

We are also grateful to the many consultants and general practitioners who routinely provide the information on which the National Registry of Childhood Tumours is based, and to the Office of Population Censuses and Surveys (now the Office for National Statistics), the Information and Statistics Division of the Common Services Agency of the Scottish Health Service, the Registrar-General for Scotland, the regional cancer registries, and the UK Children's Cancer Study Group.

We thank the many interviewers, general practitioners, consultants, and parents who have provided assistance to the Oxford Survey of Childhood Cancers. We thank Jaswant Bal and Suvineetha Wanansundara for data abstraction from the survey
- The results of this study of occupational exposure to radiation before conception of a child do not support the hypothesis that paternal preconception irradiation is a cause of childhood leukaemia or non-Hodgkin lymphoma

- The risk of leukaemia or non-Hodgkin lymphoma was significantly raised among the children of male radiation workers, but this risk was not related to preconception radiation dose; indeed, the association was greatest for the group with zero dose or doses below the level of detection

- Paternal preconception irradiation was not associated with other childhood cancers

- The risk of cancer in children of female radiation workers was significantly raised, but again there was no evidence for a relation with radiation dose; these conclusions were based on very small numbers

- The absence of a relation between dose and risk in this study leads to the conclusion that these findings may be due either to chance or to some characteristic other than exposure to radiation of the occupational groups studied. The most likely of such explanations, at least for leukaemia, is exposure to an oncogenic infective agent resulting from high levels of population mixing

for this report and Ivy Peck for reviewing record linkages. We acknowledge the pioneering work of Professor Alice Stewart in initiating and carrying forward the Oxford Survey of Childhood Cancers.

The computerised record linkage procedures used are based on a program provided by Professor Geoffrey Howe, and we are grateful for his advice concerning the use of this program.

Funding: The Childhood Cancer Research Group is supported by the Department of Health and the Scottish Home and Health Department. Professor Kinlen's Scottish study was entirely funded by the Cancer Research Campaign. Specific support for this study was received from the Department of Health and from the Health and Safety Executive.The views expressed in this publication are those of the authors and not necessarily those of the funding bodies.

Conflict of interest: None.

1 Gardner MJ, Snee MP, Hall AJ, Powell CA, Downes S, Terrell JD. Results of case-control study of leukaemia and lymphoma among young people of case-control study of leukaemia and lymphoma among young people
near Sellafield nuclear plant in west Cumbria. BMJ 1990;300:423-9.

2 Gardner MJ. Paternal occupations of children with leukaemia. BMJ 1992;305:715.

3 Stiller CA, Allen MB, Eatock EM. Childhood cancer in Britain: the national registry of childhood tumours and incidence rates 1978-1987. Eur J Cancer 1995;31A:2028-34.

4 Stewart A, Webb J, Hewitt D. A survey of childhood malignancies. BMJ 1958;i:1495-508.

5 Gilman EA, Kneale GW, Knox EG, Stewart AM. Pregnancy, X-rays and childhood cancers: effects of exposure age and radiation dose. J Radiol Prot 1988;8:3-8.

6 Kinlen LJ, Clarke K, and Balkwill A. Paternal preconceptional radiation exposure in the nuclear industry and leukaemia and non-Hodgkin's lymphoma in young people in Scotland. BMJ 1993;306:1153-8.

7 Draper GJ, Little MP, Sorahan T, Kinlen LJ, Bunch KJ, Conquest AJ, et al. Cancer in the offspring of radiation workers: a record linkage study. Chilton: National Radiological Protection Board, 1997. (Report R298.)

8 Kendall GM, Muirhead CR, MacGibbon BH, O'Hagan JA, Conquest AJ, Goodill AA, et al. First analysis of the National Registry for Radiation Workers: occupational exposure to ionising radiation and mortality. Chilton: National Radiological Protection Board, 1992. (Report R251.)

9 Howe GR, Lindsay J. A generalized iterative record linkage computer system for use in medical follow-up studies. Computers and Biomed Res 1981;14:327-40. 
10 Health and Safety Executive. HSE investigation of leukaemia and other cancers in the children of male workers at Sellafield. London: HSE, 1993.

11 Health and Safety Executive. HSE investigation of leukaemia and other cancers in the children of male workers at Sellafield: review of results published in October 1993. London: HSE, 1994.

12 United Nations Scientific Committee on the Effects of Atomic Radiation. Iomizing radiation: sources and biological effects. New York: United Nations, 1982.

13 LogXact-Turbo, Version 1.1. Cambridge, MA: Cytel Software,, 1993.

14 Breslow NE, Day NE. Statistical methods in cancer research. Vol 1. The analysis of case-control studies.Lyon: International Agency for Research on Cancer, 1982. (IARC scientific publications No 32.)

15 Preston DL, Lubin JH, Pierce DA, McConney ME. Epicure, Release 2.0. Seattle: MicroSoft International, 1996

16 McLaughlin JR, King WD, Anderson TW, Clarke EA, Ashmore JP. Paternal radiation exposure and leukaemia in offspring: the Ontario case-control study. BMJ 1993;307:959-66. (Correspondence: BMJ 1993;307:1257, 1462.)

17 Parker L, Craft AW, Smith J, Dickinson H, Wakeford R, Binks K, et al Geographical distribution of preconceptional radiation doses to fathers employed at the Sellafield nuclear installation, west Cumbria. BMJ 1993;307:966-71

18 Roman E, Watson A, Beral V, Buckle S, Bull D, Baker K, et al. Case-control study of leukaemia and non-Hodgkin's lymphoma among children aged 0-4 years living in West Berkshire and North Hampshire health districts. BMJ 1993;306:615-21.

19 Michaelis J, Kaatsch P, Zöllner I. Querschnittsuntersuchung zur Häufigkeit von Krebserkrankungen bei Kindern von beruflich strahlenexponierten Beschäftigten in westdeutschen kerntechnischen Anlagen. Arbeitsmed Sozialmed Umweltmed 1994;29:324-330, 335. (Erratum: Arbeitsmed Sozialmed Umweltmed 1995;30:78).

20 Pobel D, Viel JF. Case-control study of leukaemia among young people near La Hague nuclear reprocessing plant: the environmental hypothesis revisited. BMJ 1997;314:101-6.

21 Andersson M, Juel K, Ishikawa Y, Storm HH. Effects of preconceptional irradiation on mortality and cancer incidence in the offspring of patients given injections of Thorotrast. J Natl Cancer Inst 1994:86:1866-70.

22 Little MP. The risks of leukaemia and non-cancer mortality in the offspring of the Japanese bomb survivors and a comparison of leukaemia risks with those in the offspring of the Sellafield workforce. J Radiol Prot 1992;12:203-18. (Erratum: J Radiol Prot 1993;13:295.)

23 Yoshimoto Y, Neel JV, Schull WJ, Kato H, Soda M, Eto R, et al. Malignant tumors during the first 2 decades of life in the offspring of atomic bomb survivors. Am J Hum Genet 1990;46:1041-52.

24 Little MP, Wakeford R, Charles MW. An analysis of leukaemia, lymphoma and other malignancies together with certain categories of non-cancer mortality in the first generation offspring (F1) of the Japanese bomb survivors. J Radiol Prot 1994;14:203-18.

25 Little MP. A comparison of the risks of leukaemia in the offspring of the Japanese bomb survivors and those of the Sellafield workforce with those in the offspring of the Ontario and Scottish workforces. J Radiol Prot 1993; 13:161-75

26 Little MP, Wakeford R, Charles MW. A comparison of the risks of leukaemia in the offspring of the Sellafield workforce born in Seascale and those born elsewhere in west Cumbria with the risks in the offspring of the Ontario and Scottish workforces and the Japanese bomb survivors. $J$ Radiol Prot 1994;14:187-201.

27 Little MP, Wakeford R, Charles MW, Andersson M. A comparison of the risks of leukaemia and non-Hodgkin's lymphoma in the first generation offspring (F1) of the Danish Thorotrast patients with those observed in other studies of parental preconception irradiation. I Radiol Prot other studies

28 Nomura T. Parental exposure to X rays and chemicals induces heritable tumours and anomalies in mice. Nature 1982;296:575-7.
29 Nomura T. Paternal exposure to radiation and offspring cancer in mice: reanalysis and new evidence. J Radiat Res 1991:32(suppl 2):64-79.

30 Takahashi $\mathrm{T}$, Watanabe $\mathrm{H}$, Dohi $\mathrm{K}$, Ito A 252Cf relative biological effectiveness and inheritable effect of fission neutrons in mouse liver tumorigenesis. Cancer Res 1992;52:1948-53.

31 Kohn HI, Epling ML, Guttman PH, Bailey DW. Effect of paternal (spermatogonial) X-ray exposure in the mouse: life span, X-ray tolerance, and tumor incidence of the progeny. Radiat Res 1965;25:423-34.

32 Cosgrove GE, Selby PB, Upton AC, Mitchell TJ, Steele MH, Russell WL Lifespan and autopsy findings in the first-generation offspring of X-irradiated male mice. Mutat Res 1993;319:71-9.

33 Cattanach BM, Patrick G, Papworth D, Goodhead DT, Hacker T, Cobb L, et al. Investigation of lung tumour induction in $\mathrm{BALB} / \mathrm{cJ}$ mice following paternal X-irradiation. Int J Radiat Biol 1995;67:607-15.

34 Hawkins MM, Draper GJ, Winter DL. Cancer in the offspring of survivors of childhood leukaemia and non-Hodgkin lymphomas. $\mathrm{Br} J$ Cancer 1995;71:1335-9.

35 Doll R, Evans HJ, Darby SC. Paternal exposure not to blame. Nature 1994;367:678-80.

36 Draper GJ. General overview of studies of multigeneration carcinogenesis in man, particularly in relation to exposure to chemicals. In: Napalkov NP, Rice JM, Tomatis I, Yamasaki H, eds. Perinatal and multigeneration carcinogenesis. Lyons: International Agency for Research on Cancer 1989:275-88. (IARC scientific publications No 96.)

37 Committee on Medical Aspects of Radiation in the Environment (COMARE). Fourth Report. The incidence of cancer and leukaemia in young people in the vicinity of the Sellafield site, West Cumbria:Further studies and an update of the situation since the publication of the report of the Black Advisory Group in 1984. London: Department of Health, 1996.

38 Kinlen LJ. Can paternal preconceptional radiation account for the increase of leukaemia and non-Hodgkin's lymphoma in Seascale? BMJ 1993:306:1718-21.

39 Kinlen LJ. Evidence for an infective cause of childhood leukaemia: Comparison of a Scottish new town with nuclear reprocessing sites in Britain. Lancet 1988;ii:1323-7.

40 Kinlen LJ. Epidemiological evidence for an infective basis in childhood leukaemia. BrJ Cancer 1995;71:1-5.

41 Kinlen LJ, Dickson M, Stiller CA. Childhood leukaemia and non-Hodgkin's lymphoma near large rural construction sites, with a comparison with Sellafield nuclear site. BMJ 1995;310:763-8.

42 Stiller CA, Boyle PJ. Effects of population mixing and socioeconomic status in England and Wales, 1979-85, on lymphoblastic leukaemia in children. BMJ 1996;313:1297-300.

43 Kinlen LJ, Petridou E. Childhood leukemia and rural population movements: Greece, Italy, and other countries. Cancer Causes and Control 1995;6:445-50.

44 Petridou E, Revinthi, K, Alexander F, Haidas S, Koliouskas D, Kosmidis H, et al. Space-time clustering of childhood leukemia in Greece: Evidence supporting a viral etiology. Br J Cancer 1996;73:1278-83.

45 Alexander FE, Chan LC, Lam TH, Yuen P, Leung NK, Ha SY et al. Clustering of childhood leukaemia in Hong Kong: association with the childhood peak and common acute lymphoblastic leukaemia and with population mixing. Br J Cancer 1997;75:457-63.

46 Kinlen LJ, Craft AW, Parker L. The excess of childhood leukaemia near Sellafield: a commentary on the fourth COMARE report. J Radiol Prot 1997;17:63-71

47 Kinlen LJ, O'Brien F, Clarke K, Balkwill A, Matthews F. Rural population mixing and childhood leukaemia: effects of the North Sea oil industry in Scotland, including the area near Dounreay nuclear site. $B M J$ 1993;306:743-8.

48 Kinlen LJ, Hudson CM, Stiller CA. Contacts between adults as evidence for an infective origin of childhood leukaemia: an explanation for the excess near nuclear establishments in West Berkshire? Br J Cancer 1991;64:549-54.

(Accepted 20 October 1997)

\section{Learning from patients A suggestion}

We are in a profession where listening to the patient, listening to his or her complaints, feelings, and fears is a major part of the job. Listening can also sometimes avert a major mishap.

I am a general practitioner. It was a busy antenatal checkup day for me as usual. One woman with a three month pregnancy, without any complaints or symptoms, came for her routine checkup. Her clinical examination was normal. During her visit, she told me that she was going on vacation for about one and a half months the next day by early morning train, taking three days to reach her native place. Normally, I get an ultrasound done around 18 to 19 weeks of gestation, so I planned this for her after her return.

However, she expressed fears regarding the wellbeing of her pregnancy and asked if I could get an ultrasound done on that very day. I could understand her apprehension and ordered the test. Within an hour she came back with the report of a molar pregnancy. I explained the condition and made her cancel her trip, which she did with relief and some sadness.

A life threatening situation was averted, because I listened to the patient and complied with her reasonable request.

Kumud Chaddah, Centre for Advanced Technology, Indore, India

We welcome articles up to 600 words on topics such as $A$ memorable patient, A paper that changed my practice, My most unfortunate mistake, or any other piece conveying instruction, pathos, or humour. If possible the article should be supplied on a disk. Permission is needed from a patient or a relative if an identifiable patient is referred to. We also welcome contributions for "Endpieces," consisting of quotations of up to 80 words (but most are considerably shorter) from any source, ancient or modern, which have appealed to the reader. 